\title{
Video Games as Concepts and Experiences of the Past
}

\author{
Aris Politopoulos \\ Leiden University \\ a.politopoulos@arch.leidenuniv.nl \\ Angus Mol \\ Leiden University \\ a.a.a.mol@hum.leidenuniv.nl
}

More and more, people do not experience the past through books, museums, or even television, but through video games. This chapter discusses how these popular entertainment products provide playful and fun experiences of the past - something we refer to here as past-play for the sake of brevity. The video game industry has become a major, fast-moving player when it comes to creating, innovating, and distributing virtual representations of the past (Champion 2015). The study of such playful video game-based products as examples of virtual heritage is part of a growing field, called archaeogaming. Archaeogaming can be generally defined as 'the archaeology of digital games', with roots in a diverse set of analogue and digital archaeological themes and tools (Reinhard 2018). It also draws in a variety of tools and thinking from game studies, game user research, and computer sciences. Archaeogaming is also a movement born in and out of playful, digital scholarship that studies popular, digital culture but itself also seeks to be part of popular, digital culture (Politopoulos et al. 2019a).

How to cite this book chapter:

Politopoulos, A. and Mol, A. 2021. Video Games as Concepts and Experiences of the Past. In: Champion, E. M. (ed.) Virtual Heritage: A Guide. Pp. 81-92. London: Ubiquity Press. DOI: https://doi.org/10.5334/bck.h. License: CC-BY-NC 
In contrast to other research in the field of virtual heritage, questions of accuracy of reconstruction and scholarly standards are of secondary importance in archaeogaming - although the question 'Is this historically accurate?' frequently serves as a point of departure for many entering the field. The reason for this is that video games are not primarily (or at all) meant to be accurate reproductions of the past. Instead, they are first and foremost entertainment and artistic products that are meant to be fun. So, instead of asking 'How accurate is this digital recreation of the past in this game?' game makers and most players will ask 'How much fun am I having with (this part of) the game?' An archaeogaming type of question can then be: 'How and for whom is this part of the game, which is a digital recreation of the past, fun?' One answer may be that it is fun because it is an accurate, solidly researched representation of a thing from the past, but this is only one of the possible explanations. Other answers may be that heritage in a game provides a fun challenge (e.g., it is something tall to climb), is emotionally affecting (because it tells an upbeat or dark history), engaging, and relatable (because the player can personally relate to a character/ event/place), or makes you feel like you have gone back to the past in an actual time machine (because the game is interactive, immersive, and authentic).

Fun may not seem to offer particularly solid ground for a serious line of research, but do not be deceived by some conservative yet influential voices that tell you that making, having, or thinking about fun is not serious or productive. Fun is a highly intriguing and complex thing; we all know it when we are having it, but it is difficult to explain what it is exactly or to recreate it consistently. We often use the definition of fun as posited by cultural philosopher and game developer Ian Bogost: fun as a relation of commitment, attention, and care. The things you end up having these types of relations with is up to you to establish. However, having fun with (video) games is something that for a variety of conservative historical and economic reasons, go beyond the scope of this chapter (see Sharpe and Thomas 2019) but is somewhat of a taboo in academic circles. This is one of the reasons that a lot of archaeogaming work is done outside of traditional scholarly channels such as books and journal papers, but through social media, blogs, live-streaming, and video essays. No matter in which form it is presented, work on how video games let us create and experience the past in ways that are fun as well as personally and societally impactful is as intriguing, complex, and important as any theme in (virtual) heritage studies - although, we acknowledge, it is perhaps a bit more fun.

After providing some context to how past-play works and what forms it takes, we will review four different cases of past-play: the Assassin's Creed series, an action-adventure series set in various periods and regions of the past; Never Alone, a game that turned into a global success, co-developed by the Iñupiat, an Alaskan indigenous tribe; RoMeincraft, a project developed to raise awareness of Roman heritage in the Netherlands; and the No Man's Sky Archaeological Survey, a project developed to document the heritage of a procedurally generated galaxy with thousands of players. In each of these short reviews, we will 
answer four key questions related to heritage in games: what sort of heritages do we experience through video games, who has created these, for whom, and how are they fun? These will provide concrete examples of the potential and pitfalls of the diverse ways we play with the past in the present.

\section{How Does Past-Play Happen?}

Often described as 'magic circles', a term coined by the historian J. Huizinga in his seminal Homo Ludens (1938), games are frequently cast as things that mimic the 'actual' world. This definition of games is helpful to get a first understanding of how they provide experiences of the past: by creating a 'playground' set aside in space and time from the here and now (Politopoulos et al. 2019a). Even so, an expanding body of game studies has convincingly argued that a view of games as disconnected 'magic circles' minimizes the many ways in which this medium enduringly affects us as individuals and members of local to global communities, or how games themselves are entangled with 'outside' political, economic, social, and ideological forces (e.g., Keogh 2018; Dyer-Witheford \& De Peuter 2009).

Video games are rooted in and intertwined with a complex set of technological, cultural, and societal factors. Firstly, video games are made possible through the processing of graphics, sounds, feedback, rules, and stories by computers (Newman 2010). Secondly, and as discussed above, they are generally speaking meant to be for fun. To begin to understand how they do what they do, it is useful to view games as a blend of mechanics (game rules and computer programming), dynamics (gameplay and goals), and (visual, aural, haptic, and emotional) aesthetic components that work together to create compelling, immersive, and affective experiences. Players do not passively consume these components but interact with them by providing input to a computer; in doing so games frame their players as powerful, creative, and performative agents. Player input is reacted to and evaluated by the computer or, in the case of social games, the computer and other players (Karhulahti 2015).

It is important to realize that games are designed and crafted using a range of digital specialties, often distributed among teams of tens, hundreds, or even thousands of highly skilled people. The production and consumption of their work constitutes a growing, global, hi-tech, and competitive entertainment industry, on par with or even eclipsing movies, books, and other media industries. While public history and heritage studies, as well as art history and media studies, have looked quite extensively at how the past is negotiated in all forms of media, comparatively little has been said about how video games function in this capacity. Studies of a subset of games, so-called serious games made for history and heritage outreach, provide an exception to this. Yet, according to recent overviews of this field, the picture is not clear and more research on their effects is badly needed (Champion 2016; Koutsabasis 2017). Moreover, serious games that are specifically designed to enable understanding of and access to 

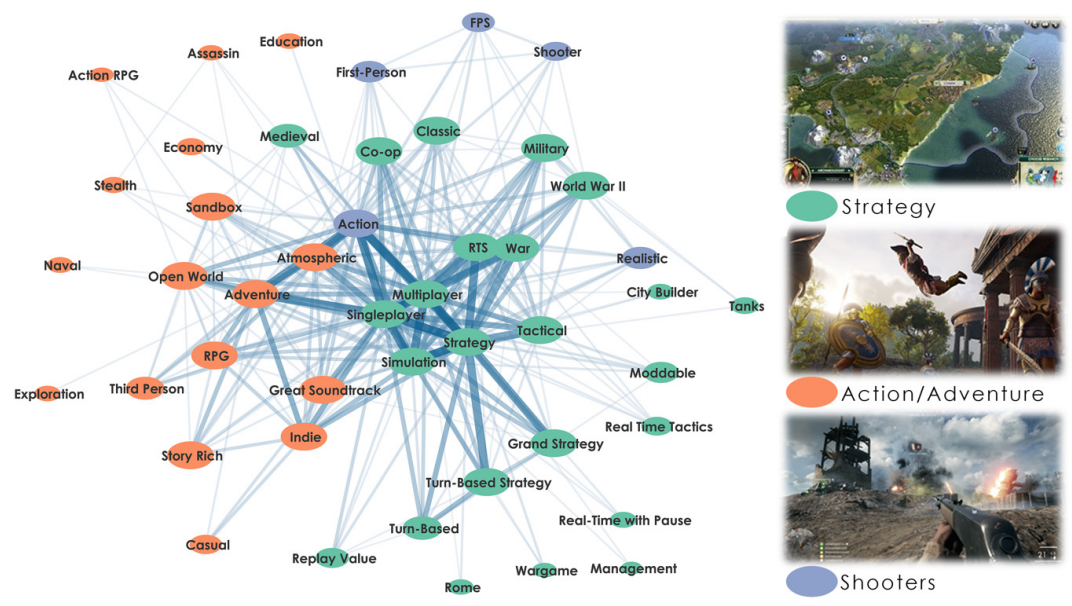

Figure 16: A network showing three 'families' of historical games, using data from Steam. Nodes represent game elements ('tags') that are identified and reported by the players of these games (produced by Angus Mol).

the past are certainly not the most impactful forms of past-play, at least in the quantitative sense. Instead, the vast majority of past-play takes place in popular games like Civilization, Assassin's Creed, and Battlefield.

\section{What Forms of Past-Play Are There?}

An estimated two billion people, or more, play games (Statista 2020). As a growing, global, and diverse community playing a large variety of game types, it is impossible to tell how many of those billions frequently play games set in the past and what sort of heritage and other experiences these games offer to them. Still, it is possible to get some sense of this by looking at what players themselves report on what they play.

We did this by using a web-scraper - a little 'robot' or computer script that collects information from specific pages on the web - that collects information on historical games on Steam, a leading game online marketplace (Mol 2019; Figure 16). Steam allows players to tag, from over 300 different types of descriptors, the games they play, which it uses to provide recommendations to all of its users. Based on the analysis of game contents tagged by millions of players, it becomes clear that most historical games build on a relatively narrow set of elements, leaning heavily on a view of history as conflict-driven (e.g., 'Action' and 'War' are commonly tagged game contents). While these games share many aspects, the study also showed they can be divided into three 'families': strategy games, action-adventure games, and first-person shooters (Figure 16). 
User and sales numbers reported by industry members can provide a first insight into the popularity of past-play. For example, Firaxis, the creator of Civilization, stated that from 2010 to 2016 people collectively played more than 1.2 billion hours of this game - eclipsing, for example, time spent in some of the world's best-visited museums (Mol et al. 2017). The maker of the Assassin's Creed series, Ubisoft, has shared that since 2007 these games have sold more than 140 million copies, making it one of the largest game franchises of the last decade. The publisher Electronic Arts stated, in a 2017 report to its shareholders, that Battlefield 1, a 2016 game set in WW1, had attracted 25 million players in a little over a year (Minotti 2018).

Given these numbers, it seems difficult to overstate the popularity of pastplay, yet high sales or engagement does not necessarily equate to cultural or societal impact. Yet some evidence already supports the idea that these popular games have a significant influence on how we relate to and think about the past, amongst which a survey of players of popular historical games recently undertaken by us and two of our students, Omar Bugter and Stefan Tibboel (Mol et al. $2020)$. For example, $93 \%$ of respondents to the survey $(n=1670)$ reported that games have inspired them to learn more about a historical person or event and $90 \%$ agree with the statement that video games can change people's viewpoints on a historical event.

Notwithstanding the deep interest individual game makers may have for history and heritage, popular historical games are traditionally and still frequently pitched as 'magic circles'. They offer forms of digital heritage that - for the sake of fun and finances and in the opinion of those in control - should be seen as separate from the cultural and societal dynamics of the 'outside' world. For example, Sid Meier, lauded game designer and creator of Sid Meier's Civilization, has stated that 'one of our fundamental goals [in making Civilization] was not to project our own philosophy or politics onto things. Playing out somebody else's political philosophy is not fun for the player.' A. Condelius (in Taylor 2018), COO of Ubisoft, the developer of the Assassin's Creed series, has similarly stated that 'People like to put politics into [our games], and we back away from those interpretations as much as we can [as they are] bad for business, unfortunately'.

Yet many smaller studios and independent creators do find new ways to provide players with an engaged, possibly fuller, sense of histories and heritages. Some of these so-called 'indie' titles also have been met with huge critical and commercial success. In addition, once a game is in the hands of its players, virtual heritage in it can take on all sorts of different shapes not intended by the developer - for example through the things players make in-game or through extensive modifications, 'mods', to the game. This provides a space for creative and surprising engagements with the past and makes new forms of virtual heritage. It is therefore important that any prospective archaeogamer has an eye for virtual heritage in a variety of forms: as produced and consumed in 


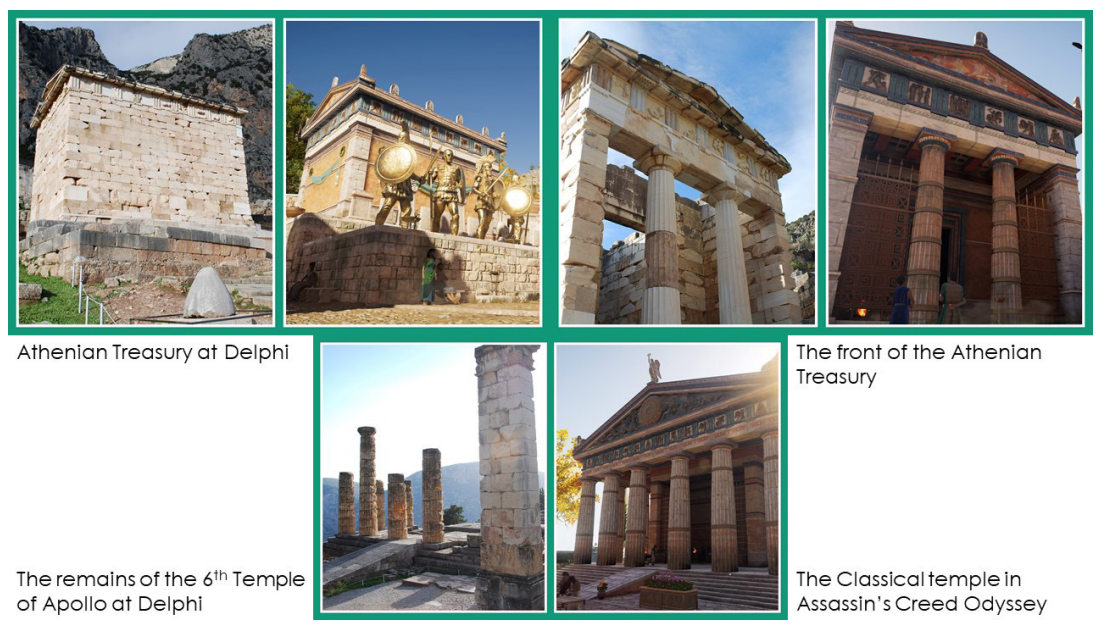

Figure 17: Buildings at Delphi in AC: Odyssey and the same locations in reality (after Politopoulos et al. 2019).

'blockbuster' games such as Assassin's Creed, through the innovative interventions of 'indies', and as created by the many people who play with the past.

\section{Assassin's Creed}

The Assassin's Creed series (AC) is one of the most popular and enduring video game series set in the past. Twenty-one AC games and spin-offs have been released since its initial appearance in 2007, across several platforms, all using various historical settings and characters. Eleven games belong to the core set of releases and can be described as third-person action-adventure games. The action-adventure aspect of the game revolves around three main mechanics: fighting, stealth, and parkour. However, as it is evident from the title of the series, killing is central to how the stories of the games play out.

The backstory of the game presents two shadowy organizations, the Assassins and the Templars, which fight for the acquisition of ancient artefacts and technologies belonging to a precursor advanced civilization. One of these technologies, the Animus, allows individuals to visit the past through memories of their ancestors. Using this as a core narrative device AC allows the player to visit multiple periods and places of the past. This broad theme, which gives an opportunity to the developers to revisit pretty much any historical (or fictional) location and time, combined with a detailed and attentive reconstruction of past places, has been central to the success of the series. This is exemplified in the highly detailed reconstruction of Athens or Delphi in AC: Odyssey, the latest addition to the series (Politopoulos et al. 2019b; Figure 17). 
All the games are developed by Ubisoft, one of the largest video game companies globally, with development studios around the world. Different development studios have been responsible for the various releases, providing a form of diversity in the development process; however, one would be hard-pressed to argue that $\mathrm{AC}$ games have been considerably different from each other, despite the diversity of settings. In that lies both the success, but also the pitfall of the series. AC games offer a widely popular yet relatively repetitive approach to both gameplay and the past. While the player gets to experience beautiful settings and meet historical characters from several periods, this experience can only be had through killing. In the end, the game creates a weird balance of killing and heritage tour, making the past an enticing yet violent place to be.

\section{Never Alone}

In Never Alone, you play as the Iñupiaq girl Nuna and Fox, who seek to find the source of a blizzard that has destroyed her village. The two-dimensional game marries platforming (i.e., jumping and running) with puzzles that can only be solved when Nuna and Fox work together. As a player you will encounter all sorts of obstacles that are part of the cultural and natural world of northern Alaskan, from being chased by a polar bear to having your head taken off by Northern Lights Spirits. The game is based on the living history and heritage of the Iñupiat (the plural for Iñupiaq), an Alaskan indigenous group. One of the game's mechanics is 'Cultural Insights', collectibles that let the players watch video interviews with Iñupiat in which they tell about all sorts of their life and histories with information that can be directly related to the puzzles, enemies, or items you as a player are encountering.

The game is the result of a co-creative process between The Cook Inlet Tribal Council (CITC), a tribal non-profit serving the Iñupiat people, and E-Line Media, a game developer originally based in Seattle. Looking for something that would be a way that would allow them to keep their traditional culture alive but also speak to the younger members of their tribe, the CITC decided to invest in game development. The story of this development of Never Alone which involved a first visit by E-Line in the middle of a January blizzard, getting the permission of the person who was the owner of the main story told in Never Alone, the creation of a unique art style based on Inupiaq art, the decision to narrate the game in Iñupiaq - is an enormous success (for the rest of this fun history, see CITC 2016). Not only did the game manage to teach Iñupiaq values and tradition to their children, but it also became a commercial and critical success.

The game is beautiful, and the Cultural Insights are enthralling, providing a window for non- Iñupiat into a world they may never visit but will come to respect or even love through play. Perhaps more importantly, it is also fun, something that is achieved through the cooperative puzzle-solving between 
Nuna and her Fox friend. As is explained in the first Cultural Insight, the idea that we are never alone is a key part of Iñupiaq worldview - the alternative title is Kisima Inyitchuya, Iñupiaq for 'I am not alone'. Making connections with others through cooperative or social gaming is a game activity that is found fun by many. The human connection at the heart of Never Alone is a great example of how mechanics and aesthetics vested in a culture's most cherished heritage, as well as a key part of the culture of gaming, come together to create something truly special and fun.

\section{RoMeincraft}

RoMeincraft is a project developed and carried out by the VALUE Foundation, of which the authors are founding members. The project's aim was to raise awareness of existing or lost Roman heritage in the Netherlands, and particularly the Dutch Limes, through the reconstruction of Roman cultural heritage sites in the popular video game Minecraft, together with the broader public (Politopoulos et al. 2019a).

Minecraft is best described as the LEGO of the video gaming world. It is an open world sandbox game without a real purpose but to build whatever the player likes. The Minecraft world consists of pixelated blocks of various materials that the player can dig up, collect, and use to construct pretty much anything. The game is offered in two modes: the survival mode, where the player is thrown in a randomly generated map and has to survive by any means necessary, and creative, where the player has limitless access to every material in the game. This latter mode is what made Minecraft ideal for our project.

For RoMeincraft, we designed scaled maps of the Netherlands (ranging between 1:2-1:4), with the locations of Roman forts being 1:1. In Minecraft every block is $1 \times 1 \times 1 \mathrm{~m}$, which makes it easier to measure space. We then conducted a number of public events in museums, plazas, and cafés, where our visitors could use one of the provided computers (or even a laptop they brought themselves) to go to a given location and start reconstruction of Roman forts. We provided players with supplementary material with historical and archaeological information about how these forts looked, but generally, players were free to construct anything they imagined would exist in Roman Netherlands. This resulted in a number of impressive constructions, several ancient Greek temples, as well as a polar bear infestation (Figure 18).

The RoMeincraft project and other projects like it show that a game does not necessarily need to be set in the past to still become an object of virtual heritage study and outreach. It is, rather, the use we make of them that has the potential to create new and engaging ways of presenting virtual heritage to a wider audience. The open and creative nature of the project gave an opportunity to visitors to engage with Roman heritage in a new way, but also in their own way, either by building in Minecraft, watching other people build, discussing, reading, 


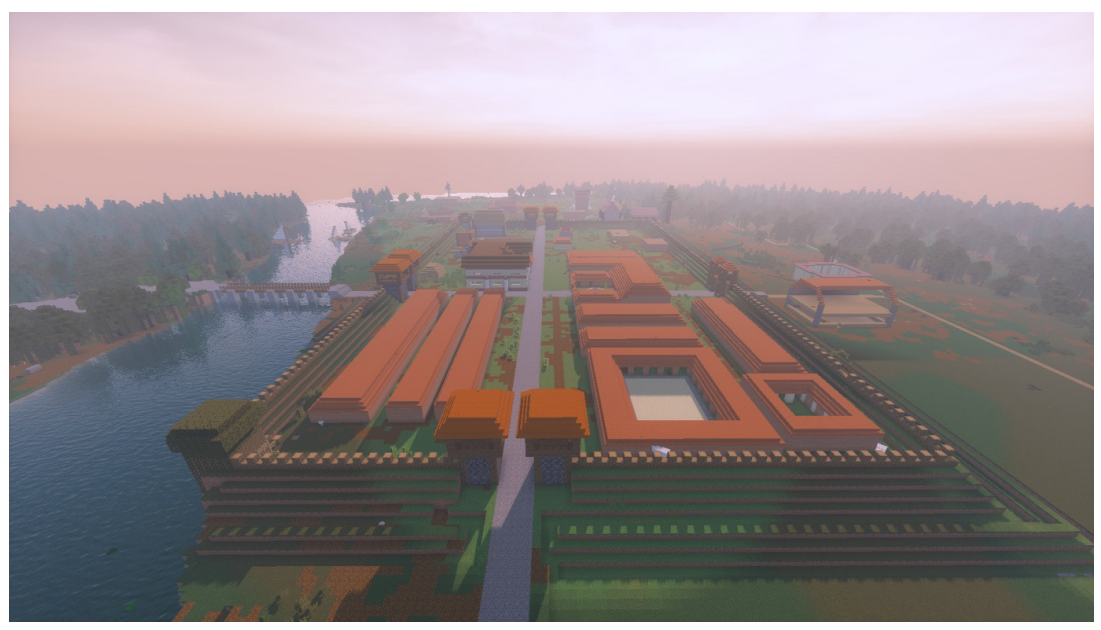

Figure 18: Screenshot of the reconstructed fort Matilo in Minecraft that had been built over several RoMeincraft events held in Leiden, 2017 (Authors).

or simply by being there and experiencing the event. This is an example of what happens when fun, rather than historical or graphical fidelity, is the aim of virtual heritage projects.

\section{The No Man's Sky Archaeological Survey}

The No Man's Sky Archaeological Survey (NMSAS) is arguably the most strictly archaeological project undertaken within a video game (Reinhard 2018: 88-160). Conducted by Andrew Reinhard as part of his PhD study, its aim was to demonstrate the viability and validity of archaeological methods for the study of digital spaces.

No Man's Sky is an online multiplayer exploration-survival game developed by Hello Games. It is set in a procedurally generated galaxy, which spawns an infinite amount of algorithmically generated planets. The player is dropped in a random location of the galaxy and has to work their way to its centre, all while visiting planets to extract resources that can either be sold or used to construct or buy equipment and improvements for the player's spaceship. The planets, however, not only contain natural landscapes but also randomly generated ruins of extinct cultures or even remains of players' settlements that have been ruined by software updates.

Reinhard implemented a full-scale community-driven survey to record all of this in a systematic manner based on the archaeological methodology of field survey. This project aimed to record now-extinct player and algorithmic heritages, as well as secure information on existing ones, before another catastrophic 
event would wipe them out. The NMSAS was opened up to Twitter and the Reddit community of the game, which allowed Reinhard to collect significantly more data than any given survey projects can realistically collect, through playing archaeology in a virtual, player-created world. This demonstrated both the importance but also the possibilities archaeogaming offers in doing research together with a wider audience as well as how it can research at larger scales and using archaeological frameworks, virtual heritage that is itself born digital. The NMSAS was both fun for its participants and offered new ways of thinking about digital spaces and heritage.

\section{Conclusion}

While many of the qualities of video games overlap with other (popular) media, the interplay of all of these - computational, fun, immersive, affective, interactive, performative, crafted, industrial, 'magic', entangled - means that games provide one-of-a-kind experiences, not only in the present but also of the past. The examples presented above highlight only some of the potential virtual heritage experiences produced through video games. It is exactly this combination of qualities alongside the wide diversity of past experiences that make video games stand out from other popular media. Video games are useful not (only) because they can offer us accurate representations of the past; in fact, one could even say that this is the least interesting of their potential uses. Rather, video games are a crucial form of digital heritage because they can offer us concepts of the past, ways of thinking in, around, and about the past, as well as experiences of the past through play.

Assassin's Creed games give players an opportunity to walk around cities of the past, and talk and interact with historical figures that you only read about in books. Games such as Never Alone, produced by indigenous populations, allow developers to safeguard cultures and players to encounter new ones virtually, and in the process provide access to concepts of the past that would otherwise remain inaccessible. The RoMeincraft project illustrates the space video games offer for promoting digital heritage, not only as educational but perhaps more so as pure play. This also underlines the co-creative and co-mediated side of heritage outreach. Finally, the No Man's Sky Archaeological Survey shows that heritage is not only something that can be put in video games but can also be born virtual. This requires new ways of studying these virtual cultures, as well as new room to play around with the concept of recent, fleeting, and borndigital pasts.

The common denominator, however, in all these experiences is fun. These games not only offer diverse approaches to share, study, and create virtual heritage through past-play past, but also as a relation built on commitment, attention, and care - in other words as something fun. Work in archaeogaming and other forms of past-play has already shown some of the potential of 
games but the breadth of experiences that can be had in these games as virtual heritages shows that there is much more to be done and much more fun to be had.

\section{References}

Champion, E 2015 Critical Gaming: Interactive History and Virtual Heritage. London: Routledge.

Champion, E 2016 Entertaining the similarities and distinctions between serious games and virtual heritage projects. Entertainment Computing, 14: $67-74$.

Cook Inlet Tribal Council (CITC) 2017 Storytelling for the next generation: How a non-profit in Alaska harnessed the power of video games to share and celebrate cultures. In: Mol, A.A.A., Ariese-Vandemeulebroucke, C. E., Boom, K. H., \& Politopoulos, A. (eds.) The interactive past: Archaeology, heritage, and video games. Leiden: Sidestone Press, 21-32.

Dyer-Witheford, N and De Peuter, G 2009 Games of empire: Global capitalism and video games. Minnesota: University of Minnesota Press.

Huizinga, J 1938 Homo Ludens: Proeve Eener Bepaling Van Het Spel-Element Der Cultuur. Amsterdam: University Press.

Karhulahti, V-M 2015 Do videogames simulate? Virtuality and imitation in the philosophy of simulation. Simulation \& Gaming, 46(6): 838-856.

Keogh, B 2018 A play of bodies: How we perceive video games. Cambridge MA: MIT Press.

Koutsabasis, P 2017 Empirical evaluations of interactive systems in cultural heritage: A review. International Journal of Computational Methods in Heritage Science 1: 100-122.

Minotti, M 2018 Jan. 30 EA's Battlefield 1 hits 25 million players thanks to DLC and discounts. Retrieved from https://venturebeat.com/2018/01/30 /eas-battlefield-1-hits-25-million-players-thanks-to-dlc-and-discounts/

Mol, A A A, Politopoulos, A, and Ariese-Vandemeulebroucke, C E 2017 From the stone age to the information age: History and heritage in Sid Meier's Civilization VI. Advances in Archaeological Practice, 5(2): 214-219.

Mol, A A A, Politopoulos, A, Tiboel, S and Bugter, O 2020 Historical game players and their experiences of the past: Raw survey data. VALUE Foundation. Retrieved from https://interactivepasts.com/value-survey/

Newman, J A 2013 Videogames. New York and London: Routledge.

Politopoulos, A, Ariese, C E, Boom, K H J, and Mol, A A A 2019a Romans and rollercoasters: Scholarship in the digital playground. Journal of Computer Applications in Archaeology, 2(1): 163-175.

Politopoulos, A, Mol, A A A, Boom, K H J, and Ariese, C E 2019b "History is our playground": Action and authenticity in Assassin's Creed: Odyssey. Advances in Archaeological Practice, 7(3): 317-323. 
Reinhard, A 2018 Archaeogaming: An Introduction to Archaeology in and of Video Games. New York: Berghahn Books.

Sharp, J and Thomas, D 2019 Fun, Taste, and Games: An Aesthetics of the Idle, Unproductive, and Otherwise Playful. Cambridge MA and London: The MIT Press.

Statista 2020. Number of active video gamers worldwide from 2014 to 2021. Retrieved from https://www.statista.com/statistics/748044/number-video -gamers-world/

Taylor, H 2018 Oct. 17 Ubisoft Massive COO: "We don't want to take a stance in current politics". Retrieved from https://www.gamesindustry.biz /articles/2018-10-17-ubisoft-massive-coo-we-dont-want-to-take-a-stance -in-current-politics 